\title{
In vivo Adsorption of Isoagglutinins with Incompatible Red Blood Cell Transfusion in Stem Cell Transplant Recipients
}

\author{
Rainer Moog \\ German Red Cross Blood Donor Service North-East, Institute Cottbus, Cottbus, Germany
}

In the first issue 2016 of Transfusion Medicine And HemoTHERAPY the transfusion support for ABO-incompatible stem cell transplantation is reviewed $[1,2]$. The authors focus on reduction of recipient isoagglutinins by plasmapheresis and red blood cell (RBC) depletion of the graft to avoid immune-hematologic consequences of ABO-incompatible stem cell transplantation. The old, nearly forgotten method of in vivo adsorption of recipient isoagglutinins was cited but not extensively mentioned although it is a simple, low-cost technique to circumvent immediate and delayed hemolysis after ABO-incompatible stem cell transplantation [3-5].

Our transfusion/transplant team has successfully performed $\mathrm{ABO}$-incompatible transfusions with donor type $\mathrm{RBCs}$ in $\mathrm{ABO}$ major-incompatible stem cell transplantation up to a recipient isoagglutinin titer of 1:32. ABO-incompatible RBCs were slowly transfused monitoring vital signs at an intensive care unit. Isoagglutinin titers were controlled after each ABO-incompatible transfusion using standard laboratory techniques. In the case of O/A recipientdonor blood group constellation we started adsorption of recipients' Anti-A with one or two units of $\mathrm{A}_{2}$ - RBCs followed by transfusion of $A_{1}-R B C s$ with a higher number of $A$-antigens per $R B C$. Using the technique of in vivo adsorption of isoagglutinins recipients' anti-A or anti-B titer were reduced thereby allowing a safe infusion of the graft. Of note, Scholl and co-workers [5] reported not only on the lack of severe complications of in vivo adsorption of donor-type RBCs but also on a significant reduction of the demand of RBC transfusion between transplantation and day 30 .

In vivo adsorption of isoagglutinins with donor-type RBCs is easy to perform and is more cost-effective than plasmapheresis. Furthermore, $\mathrm{ABO}$-incompatilbe transfusion in mismatched stem cell transplantation avoids graft manipulation ensuring the quality of an un-manipulated graft.

\section{References}

1 Worel N: ABO-mismatched allogeneic hematopoietic stem cell transplantation. Transf Med Hemother 2016; 43:3-12.

2 Kopko PM: Transfusion support for ABO-incompatible progenitor cell transplantation. Transfus Med Hemother 2016;43:13-18.
3 Nussbaumer W, Schwaighofer H, Gratwohl A, et al: Transfusion of donor-type red cells as a single preparative treatment for bone marrow transplants with major ABO incompatibility. Transfusion 1995;35:592-595.

4 Tichelli A, Gratwohl A, Nissen C, et al: ABO-incompatible bone marrow transplantation: three methods for the removal of red blood cell antibodies. Transfus Apher Sci 1987;8:355-359.
5 Scholl S, Klink A, Mugge LO, Schilling K, Hoffken K, Sayer HG: Safety and impact of donor-type red blood cell transfusion before allogeneic peripheral blood progenitor cell transplantation with major $\mathrm{ABO}$ mismatch. Transfusion 2005;45:1676-1683.

\section{KARGER \\ Fax +497614520714

Prof. Dr. Rainer Moog 